\title{
ALGUMAS CONTRIBUIÇÕES DE BAKHTIN, SCHNEUWLY E ADAM PARA OS ESTUDOS SOBRE GÊNEROS
}

\author{
Sebastião Carlúcio Alves-Filho (UFG) \\ cbastian2@gmail.com \\ Sílvio Ribeiro da Silva (UFG) \\ shivonda@gmail.com
}

\section{Introdução}

Silva (2008) comenta que os gêneros são uma preocupação constante desde Aristóteles e Platão. Segundo o autor, o surgimento da noção de gênero se dá com o início da oratória, desenvolvida a partir da instauração da democracia na Grécia. Para Fiorin (2006), nesta época, textos já eram agrupados de acordo com suas características em comum ${ }^{4}$. De início, estes eram distribuídos em três categorias bastante sólidas que, depois, se subdividiram. Hoje, a noção de gênero foi ampliada para todo tipo de produção textual e/ou discursiva, seja ela escrita ou oral.

De acordo com Ramires (2005, p. 01),

Nos últimos trinta anos, pesquisadores de diferentes áreas de conhecimento têm-se dedicado mais sistematicamente ao estudo de gêneros e isso pode ser confirmado pela crescente expansão do número de publicações que tratam especificamente desse tema.

No Brasil, por volta de 1995, grande atenção foi direcionada às teorias de gênero por estudiosos de Linguística Aplicada (LA). Isso se deve, ao menos em parte, aos novos referenciais nacionais de ensino de línguas, que propõem explicitamente, como objeto de ensino, o trabalho com gêneros. Esses referenciais também destacam a importância de considerar as características dos gêneros na leitura e na produção de textos (ROJO, 2005). Em se tratando da produção de textos, esses referenciais deram novo direcionamento ao seu ensino,

\footnotetext{
${ }^{4}$ Em sua Retórica (Livro I [1354]), Aristóteles concebe três gêneros, ou três espécies de Retórica (JÚNIOR, 1998): deliberativo ou político, forense ou judicial e de exibição (epidítico) ou demonstrativo (ARISTÓTELES, 1998). Segundo o filósofo, a situação do discurso consiste num orador, num discurso e num auditório. $\mathrm{O}$ auditório ou é juiz (no tribunal), ou espectador (no conselho ou assembleia).
} 
sendo, este, desenvolvido à luz da perspectiva dos gêneros e não mais pela ótica dos tipos textuais. Essa mudança de direção foi essencial para que esse ensino também mudasse, tendo em vista que, segundo Schneuwly \& Dolz (2004, p. 74), "é através dos gêneros que as práticas de linguagem materializam-se nas atividades dos aprendizes".

Vários pesquisadores se ocuparam em estudar e caracterizar a noção de gênero. Isso fez com que surgissem diferentes abordagens acerca desse tema. Rojo (2005) nos diz que esses estudos podem ser divididos em duas vertentes teóricas: a dos gêneros do discurso e a dos gêneros de texto. A primeira centra-se, sobretudo, no estudo das situações de produção dos enunciados, e a segunda na descrição da materialidade textual. Sobre isso, Reinaldo (2002, p. 02) afirma que

Essa variação de critérios leva à sobreposição, e às vezes, à diferenciação entre os conceitos de tipo/gênero textuais, de(o) discurso. De modo geral, denominam-se gêneros textuais os textos particulares, que apresentam organização textual, funções sociais, produtor e destinatário definidos; e gêneros discursivos, aqueles que se caracterizam segundo critérios como fator de economia cognitiva, rotina, atividade social, finalidade reconhecida, interlocutores legítimos, lugar e tempo legítimos, suporte material e organização textual.

Ainda que os estudos sobre gêneros sejam apresentados sobre abordagens diferentes, "existe como ponto em comum entre eles o fato de reconhecerem, explicitamente, a primazia do social na compreensão dos gêneros e no papel do contexto" (RAMIRES, 2005, p. 03).

Pensando nisso, apresentamos neste trabalho uma visão panorâmica sobre as contribuições de Bakhtin, Schneuwly e Adam para o estudo sobre gêneros, para ser possível vislumbrar até que ponto suas teorias se diferem ou se interagem. Isso porque os autores citados são responsáveis por apresentar importantes e diferentes abordagens sobre o tema, contribuindo de forma significativa para o estudo sobre gêneros e suas aplicações.

\section{A teoria dos gêneros do discurso proposta por Bakhtin}

Não se pode falar em gêneros, segundo Ramires (2005), sem comentar a grande contribuição de Bakhtin para os estudos sobre esse tema. Isso porque o filósofo russo é considerado uma das referên- 
cias mais relevantes nos estudos sobre gêneros. Seus postulados sobre a linguagem estabeleceram um marco na linguística moderna e orientaram a maioria das teorias de enunciação conhecidas até hoje. Barros (2005, p. 25) comenta que

Bakhtin influenciou ou antecipou as principais orientações teóricas dos estudos sobre o texto e o discurso desenvolvidos, sobretudo, nos últimos 30 anos.

Ao contrário do empreendido pelos estudos linguísticos, que tomaram a língua por objeto e começaram pela busca de unidades mínimas ou de unidades até a dimensão da frase, Bakhtin afirma que a especificidade das ciências humanas está no fato de que seu objeto é o texto (ou discurso). Em outras palavras, as ciências humanas se voltam para o homem, mas é o homem como produtor de textos que se apresenta aí (BARROS, 2005, p. 26).

A teoria dos Gêneros do Discurso, proposta por Bakhtin, leva em consideração o fato de que a língua é um instrumento de interação. Para o autor, somente a interação entre dois indivíduos socialmente organizados pode dar origem à enunciação. Mesmo que não haja interlocutor real, este pode ser substituído por um representante do mesmo grupo social ao qual pertence o locutor (RODRIGUES, 2005).

Nesse sentido, os conceitos apresentados por Bakhtin têm, como eixo central, a ideia de que o uso da linguagem acontece no interior das relações sociais mantidas pelos indivíduos (RAMIRES, 2005). "Todos os diversos campos da atividade humana estão ligados ao uso da linguagem" (BAKHTIN, 1979, p. 261). Para Bakhtin (1979, p. 261), "a situação social mais imediata e o meio social mais amplo determinam completamente e, por assim dizer, a partir de seu próprio interior, a estrutura da enunciação".

Falamos sempre por meio de gêneros numa dada esfera de atividade humana, e é o contexto que determina as características do gênero a ser utilizado. "Cada campo de utilização da língua elabora seus tipos relativamente estáveis de enunciados" (BAKHTIN, 1979, p. 280). Rodrigues (2005, p. 164) comenta que

Cada esfera, com sua função socioideológica particular (estética, educacional, jurídica, religiosa, cotidiana etc.) e suas condições concretas específicas (organização socioeconômica, relações sociais entre os participantes da interação, desenvolvimento tecnológico etc.), historicamente formula na/para a interação verbal gêneros discursivos que lhe são pró- 
prios. Os gêneros se constituem e se estabilizam historicamente a partir de novas situações de interação verbal (ou outro material semiótico) da vida social que vão se estabilizando, no interior dessas esferas.

Para Bakhtin (1979), o processo de interação cria enunciados que refletem as condições específicas e as finalidades de determinado campo da linguagem não apenas pelo seu tema e estilo, mas, acima de tudo, por sua construção composicional.

O tema é, de acordo com Fiorin (2006), o domínio de sentido de que se ocupam os gêneros, e não apenas o assunto específico do texto. O tema deve ser único, sendo uma propriedade que pertence a cada enunciação como um todo, desde os elementos linguísticos até os não verbais. É o que pode tornar-se dizível por meio dos gêneros ${ }^{5}$.

Bakhtin/Volochínov (1981, p. 126) comenta que "o tema da enunciação é, na verdade, assim como a própria enunciação, individual e reiterável. Ele se apresenta como a expressão de uma situação histórica concreta que deu origem à enunciação".

Fiorin (2006) nos diz que o estilo pode ser caracterizado como a seleção de meios linguísticos, ou seja, de meios lexicais, fraseológicos e gramaticais em função da imagem do interlocutor e de como se presume sua compreensão responsiva ativa do enunciado. Está relacionado à seleção e opção de vocabulário, preferências gramaticais, estruturas frasais, não só relacionados ao gênero, mas também ao autor ${ }^{6}$.

\section{Para Bakhtin (1992, p. 265),}

Todo enunciado - oral e escrito, primário e secundário e também em qualquer campo de comunicação discursiva - é individual e por isso pode refletir a individualidade do falante (ou de quem escreve), isto é, pode ter estilo individual. Entretanto, nem todos os gêneros são

\footnotetext{
${ }^{5}$ Em geral, o próprio gênero estabelece para si pautas temáticas e formas típicas de tratamento do tema. Segundo Costa Val (2003), nas diferentes instâncias de uso da língua, se estabelecem diferentes expectativas quanto ao leque de assuntos pertinentes ou impertinentes, permitidos ou proibidos, e quanto ao grau de autenticidade, fidedignidade e exaustividade de sua abordagem.

${ }^{6}$ Podemos citar como exemplo as opções que faz um autor de novelas em relação às escolhas referentes à sua obra. Glória Peres apresenta um estilo de autor relacionado à apresentação de aspectos culturais de outra comunidade (os ciganos, em Explode Coração, os muçulmanos, em $\mathrm{O}$ Clone, os hindus, em Caminhos das Índias, para citar alguns casos).
} 
igualmente propícios a tal reflexo da individualidade do falante na linguagem do enunciado.

Da Silva (2008) comenta que os gêneros do discurso que requerem uma forma padronizada, como formulação de documentos oficiais, ordem militar, nota de serviço etc., apresentam condições menos favoráveis para refletir a individualidade da língua.

Fiorin (2006) apresenta a construção composicional como sendo o modo de organizar o texto, de estruturá-lo, apontando para suas formas de organização, as partes que o compõe e como elas se distribuem. Schneuwly \& Dolz (2004) nos dizem que fazem parte da construção composicional os elementos das estruturas comunicativas e semióticas compartilhadas pelos textos pertencentes ao gênero ${ }^{7}$.

Por existirem várias esferas de comunicação, se faz necessário que os indivíduos se utilizem da linguagem de diferentes formas para que atinjam determinados objetivos. Isso faz com que exista uma infinidade de gêneros do discurso que se concretizam nas mais diversas situações de uso da linguagem. Sobre isso, pode-se dizer que

A riqueza e a diversidade dos gêneros do discurso são infinitas porque são inesgotáveis as possibilidades da multiforme atividade humana e porque em cada campo dessa atividade é integral o repertório de gêneros do discurso, que cresce e se diferencia à medida que se desenvolve e se complexifica um determinado campo (BAKHTIN, 1979, p. 262).

Segundo Bakhtin (1979), a grande quantidade de gêneros do discurso existente faz com que seja praticamente impossível que todos eles sejam catalogados. Nesse sentido, o autor considera importante destacar a existência de gêneros primários (simples) e de gêneros secundários (complexos).

Ramires (2005) afirma que os gêneros primários se constituem de enunciados proferidos em circunstâncias de comunicação verbal espontânea e servem de base para constituição dos gêneros secundários. Estes, segundo Bakhtin (1979), surgem nas condições de interação, as quais se apresentam em situações de um convívio cultural

\footnotetext{
${ }^{7}$ Podemos pensar na construção composicional como a arquitetura do gênero. Como exemplo, podemos imaginar um e-mail, que sempre tem o mesmo formato físico.
} 
mais complexo, mais desenvolvido e organizado. Ao elaborar enunciados que se enquadram nesta perspectiva, o locutor incorpora a eles formas reelaboradas dos diversos gêneros primários.

\section{A teoria dos gêneros textuais proposta por Schneuwly}

Rojo (2005) nos diz que é bem antiga a ideia de que o texto é a base do ensino-aprendizagem de Língua Portuguesa. No Brasil, esse princípio vem sendo firmado por diversos programas e propostas curriculares. Antunes (2005) afirma que o texto falado, ouvido, lido e escrito é (ou ao menos deveria ser) o objeto principal das aulas de Língua Portuguesa. Não tem sentido aprender os diversos conceitos gramaticais se não se sabe como usá-los em textos e quais são as funções que esses termos exercem para que se mantenha coesão e coerência naquilo que se quer dizer.

Nesse sentido, a corrente teórica que mais fortemente se voltou para a questão do ensino de língua, segundo Ramires (2005), é a perspectiva adotada pelos estudiosos que compõem a Escola de Genebra. Dentre estes estudiosos, está Bernard Schneuwly, um dos primeiros autores a fazer esse tipo de abordagem.

Na concepção do autor, os gêneros são o instrumento que nos permite fazer o uso da língua ${ }^{8}$. Ele ainda comenta que um sujeito que age discursivamente (fala/escreve), numa dada esfera social, se utiliza de um determinado gênero como instrumento semiótico complexo, isto é, "uma forma de linguagem prescritiva, que permite, a um só tempo, a produção e a compreensão de textos" (SCHNEUWLY, 2004, p. 27).

A definição dos parâmetros que guiam a situação de interação é determinante para que se faça a escolha do gênero textual a ser utilizado. Essa tese, levantada por Schneuwly, visa comprovar que o

\footnotetext{
${ }^{8} \mathrm{~A}$ menção do autor ao gênero como instrumento está vinculada às suas ideias sobre 0 ensino. Segundo ele, o gênero é um instrumento de comunicação em uma determinada situação, mas, ao mesmo tempo, um objeto de ensino/aprendizagem. O gênero pode ser considerado um megainstrumento que fornece um suporte para a atividade nas situações de comunicação e uma referência para os aprendizes.
} 
gênero é um instrumento que media a relação entre sujeito e linguagem.

Seguindo a perspectiva teórica de Bakhtin, Dolz \& Schneuwly (2004, p. 52) consideram que todo gênero se define por três dimensões essenciais:

1) Os conteúdos que são (que se tornam) dizíveis através dele;

2) A estrutura (comunicativa) particular dos textos pertencentes ao gênero;

3) As configurações específicas das unidades de linguagem, que são sobretudo traços da posição enunciativa do enunciador, e os conjuntos particulares de sequências textuais e de tipos discursivos que formam sua estrutura.

Schneuwly (2004, p. 29), ao falar sobre os gêneros primários e secundários (propostos por Bakhtin) retoma as sugestões do autor, no que tange à distinção entre os dois, definindo as seguintes dimensões para aqueles:

- Troca, interação, controle mútuo pela situação;

- Funcionamento imediato do gênero como entidade global controlando todo processo, como uma só unidade;

- Nenhum, ou pouco controle metalinguístico da ação linguística em curso.

Para o autor, os gêneros secundários não são controlados diretamente pela situação, funcionando psicologicamente por entidades separadas e necessitando de outros mecanismos de controle mais potentes. A diferença entre o gênero primário e o secundário está no tipo de relação com a ação, linguística ou não. É na ação da linguagem que o gênero primário se estabelece; e é por meio de outros mecanismos que o gênero secundário se estabelece.

Schneuwly (2004) nos diz que os gêneros são ótimos instrumentos para ensinar e aprender língua. Quanto mais gêneros são apropriados, maiores são as capacidades de se usar a língua. Para esclarecer como os gêneros são instrumentos privilegiados para a aprendizagem, o autor considera que toda a aprendizagem se dá não individualmente, mas nas interações sociais. Então, os gêneros são objetos que usamos para nos comunicar, instrumentos de comunica- 
ção socialmente elaborados ou, dizendo de outra maneira, instrumentos da comunicação entre as pessoas. Mas o instrumento só é útil como mediador se o sujeito se apropriar dele. Nesse sentido, o autor (p. 24) postula que "O instrumento, para se tornar mediador, para se tornar transformador da atividade, precisa ser apropriado pelo sujeito; ele não é eficaz senão à medida que se constroem, por parte do sujeito, os esquemas de sua utilização".

Schneuwly se apoiou nas considerações de Bakhtin acerca dos gêneros para criar um dos seus mais comentados estudos sobre gêneros e tipos textuais, intitulado Gêneros e tipos textuais: considerações psicológicas e ontogenéticas. Neste, o autor faz, segundo Ramires (2005), uma reflexão sobre as relações existentes entre tipos e gêneros e características dos gêneros secundários, além de defender que o gênero pode ser considerado como um instrumento psicológico, seguindo o sentido vygotskiano do termo.

\section{A teoria das sequências textuais proposta por Adam}

Já em seus primeiros trabalhos, Adam propunha uma reflexão teórica que agrupasse as orientações formais e enunciativas a respeito do texto. $\mathrm{O}$ autor começou a definir a noção de sequência no decorrer da década de 1980, aprofundando-se mais nesse assunto posteriormente em trabalhos publicados a partir dos anos 1990 (BONINI, 2005).

Bonini (2005) comenta que, tendo por base o conceito proposto por Bakhtin, que propõe duas categorias de gêneros (primários e secundários), Adam se vale da ideia de estabilidade ao propor que os gêneros primários sejam vistos como tipos nucleares e responsáveis pela estruturação dos gêneros secundários. Nesse sentido, os gêneros primários são concebidos como sequências textuais, ou seja, como componentes textuais que compõem os gêneros secundários.

Adam desenvolve a noção de sequências textuais tendo por base a hipótese de existência de unidades mínimas de composição textual, ou seja, protótipos. Estes "são modelos abstratos de que os produtores e receptores de textos disporiam, disponíveis, ao mesmo tempo, pela natureza das macroproposições que comportam e pelas 
modalidades de articulação dessas macroproposições em uma estrutura autônoma" (BRONCKART, 2003, p. 218).

Nesse sentido, segundo Bonini (2005), Adam propõe sete tipos de sequências': (i) narrativa; (ii) descritiva; (iii) argumentativa; (iv) expositivo-explicativa; (v) injuntivo-instrucional; (vi) conversacional e (vii) poético-autotélica). Posteriormente, o autor reduz esse número para apenas cinco: (i) narrativa; (ii) descritiva; (iii) explicativa; (iv) argumentativa e (v) dialogal. Exclui a injuntiva, por considerar que esta é parte da descrição, e a poética por considerar que o texto poético não é exatamente uma estrutura hierárquica e ordenada por proposições, mas sim o resultado dos ajustes de superfície na base do texto.

Em sua teoria, de acordo com Sousa (2007, p. 1503),

Adam mostra que os textos compõem-se de sequências, que são, sob determinados aspectos, independentes, ou seja, cada uma, em si mesma, possui traços característicos que a individualizam; contudo, são dependentes sob outros aspectos, pois não existem à revelia dos gêneros textuais. Sob este ângulo, elas não são autônomas. Enquanto os gêneros textuais englobam um número maior de ocorrências no meio social, as sequências aparecem de forma mais simplificada e, em um mesmo gênero, podem-se encontrar várias sequências.

Segundo Sousa (2007), Adam rejeita a utilização do termo "tipos textuais", visto que o texto é extremamente complexo e heterogêneo e, por isso, não estaria sujeito a tais regularidades linguísticas que essa terminologia sugere. Com isso, as unidades identificadas como narração, descrição, argumentação, explicação e diálogo são situadas em um nível menos elevado, dentro da complexidade composicional que ele concebe.

A partir desses conceitos, Pereira (s/d: 05) afirma que,

No quadro teórico da linguística textual, elaborado por Jean-Michel Adam, uma sequência textual é uma unidade textual relativamente autônoma e dotada de uma organização interna própria, tanto da ordem semântica quanto formal, hierarquicamente situada entre o nível inferior dos períodos e o nível superior englobante do texto.

\footnotetext{
${ }^{9}$ Por conta de pouco espaço de que dispomos não será possível entrar em detalhes acerca do que é cada uma dessas sequências.
} 
Adam se apoiou no conceito de gênero proposto por Bakhtin, que o define como tipos relativamente estáveis de enunciados; no conceito de enunciado como unidade concreta de texto; e, principalmente, na subdivisão dos gêneros em primários e secundários para construir o conceito de sequência textual. Segundo Catunda (2005, p. 186),

É dessa ideia de estabilidade e de que os gêneros primários são tipos nucleares menos heterogêneos e responsáveis pela estruturação dos gêneros secundários, que Adam os concebe com sequências textuais, compostos por preposições relativamente estáveis.

\section{Considerações finais}

A noção de gênero, segundo Ramires (2005), rompe definitivamente com as abordagens tradicionais sobre a língua e com as abordagens estruturalistas, as quais não respondem, na maioria das vezes, muitas dúvidas e inquietações que se colocaram para os estudos centrados na palavra. A forma de entender o que vem a ser gênero varia, sendo encontradas algumas diferentes abordagens teóricas.

Neste trabalho, buscamos fazer um brevíssimo panorama das contribuições de Bakhtin, Schneuwly e Adam para os estudos sobre gênero. Ao final, foi possível concluir que existem muitos pontos em comum entre as três teorias apresentadas. Isso acontece, pois alguns autores aproveitaram estudos anteriores como base para a criação de novas ideias.

O quadro a seguir apresenta, em síntese, o que cada autor considera sobre o tema.

\begin{tabular}{|c|l|}
\hline Gêneros do discurso (Bakhtin) & São produtos da interação verbal \\
\hline Gêneros textuais (Schneuwly) & $\begin{array}{c}\text { São instrumentos privilegiados para a } \\
\text { aprendizagem }\end{array}$ \\
\hline Sequências textuais (Adam) & $\begin{array}{c}\text { São componentes textuais dos quais os } \\
\text { gêneros são compostos }\end{array}$ \\
\hline
\end{tabular}

Principais características das teorias sobre gêneros 


\section{REFERÊNCIAS BIBLIOGRÁFICAS}

ANTUNES, I. Lutar com as palavras: coesão e coerência. São Paulo: Parábola, 2005.

ARISTÓTELES. Retórica. Lisboa: INCM, 1998.

BAKHTIN, M. Os gêneros do discurso. In: verbal. São Paulo: Martins Fontes, 1979, p. 277-326.

BAKHTIN; M. M.; VOLOSHINOV, V. N. Marxismo e filosofia da linguagem. São Paulo: Hucitec, 1981.

BONINI, A. Os gêneros do jornal: questões de pesquisa e ensino. In. KARWOSKI, A. M.; GAYDECZKA, B.; BRITO, K. S. Gêneros textuais: reflexões e ensino. Rio de Janeiro: Lucerna, 2006.

BRONCKART, J. P. Atividade de linguagem, textos e discurso. São Paulo: Educ, 2003.

BARROS, D. L. P. Contribuições de Bakhtin às teorias do discurso. In. BRAIT, B. Bakhtin: dialogismo e construção do sentido. Campinas: Unicamp, 2005.

CATUNDA, E. L. A perspectiva funcional da sequência narrativa como organizadora do processo jurídico. In: Caderno de resumos IX Congresso Nacional de Linguística e Filologia, Rio de Janeiro: CiFEFiL, 2005, v. 2.

COSTA VAL, M. da G. C. Atividades de Produção de Textos Escritos em Livros Didáticos de $5^{\mathrm{a}}$ à $8^{\mathrm{a}}$ séries do Ensino Fundamental. In: ROJO, R. \& BATISTA, A. A. Livro didático de língua portuguesa, letramento e cultura da escrita. Campinas: Mercado de Letras, 2003, p. $125-152$.

DOLZ, J. \& SCHNEUWLY, B. Gêneros e progressão em expressão oral e escrita: elementos para reflexões sobre uma experiência suíça (francófona). In: SCHNEUWLY, B., DOLZ, J. et al. Gêneros orais e escritos na escola. Campinas: Mercado de Letras, 2004, p. 41-70.

FIORIN, J. L. Os gêneros do discurso. In: FIORIN, J. L. Introdução ao pensamento de Bakhtin. São Paulo: Ática, 2006, p. 60-76. 
JÚNIOR, M. A. Introdução da retórica de Aristóteles. In: ARISTÓTELES. Retórica. Lisboa: INCM, 1998.

PEREIRA, R. A. Tipologias textuais. Disponível em:

$\langle$ https://woc.uc.pt/fluc/getFile.do?tipo=2\&id=2205>. Acesso em: 13 maio 2010.

RAMIRES, V. Panorama dos estudos sobre gêneros textuais. Investigações (Recife), Recife, v. 18, n. 18, p. 39-67, 2005.

REINALDO, M. A. G. Que concepções teóricas de gênero textual estão subjacentes às questões discursivas do ENEM? XIX Jornada de Estudos Linguísticos, 2002.

RODRIGUES, H. R. Os gêneros do discurso na perspectiva dialógica da linguagem. In: Gêneros: teorias, métodos, debates. São Paulo: Parábola, 2005.

ROJO, R. H. R. Gêneros do discurso e gêneros textuais: questões teóricas e aplicadas. In: Gêneros: teorias, métodos, debates. São Paulo: Parábola, 2005.

SCHNEUWLY, B. Gêneros e tipos de discurso: considerações psicológicas e ontogenéticas. In: SCHNEUWLY, B. \& DOLZ, J. et al. In: Gêneros orais e escritos na escola. Campinas: Mercado de Letras, 2004, p. 21-39.

SCHNEUWLY, B. \& DOLZ, J. Os gêneros escolares - das práticas de linguagem aos objetos de ensino. In: SCHNEUWLY, B. \& DOLZ, J. et al. Gêneros orais e escritos na escola, Campinas: Mercado de Letras, 2004, p. 71-91.

SILVA, S. R. da. Teoria aplicada sobre gêneros do discurso/textuais. Disponível em: <htpp://www.filologia.org.br>. Acesso em: 13 maio 2010.

SOUSA, M. M. F. A inter-relação entre as sequências textuais e os processos de referenciação anafórica no gênero anúncio. In: BONINI, A.; FIGUEIREDO, D. de C.; RAUEN F. J. (Org.). Anais proceedings. Santa Catarina: Tubarão, 2007. 